\title{
Initial experience of using the filter protection device during carotid artery stenting in Japan
}

\author{
Katsutoshi Takayama $\cdot$ Hiroyuki Nakagawa \\ Satoru Iwasaki · Toshiaki Taoka · Toshiteru Miyasaka \\ Kaoru Myouchin · Takeshi Wada · Masahiko Sakamoto \\ Akio Fukusumi · Ichiro Nakagawa \\ Shinichiro Kurokawa $\cdot$ Kimihiko Kichikawa
}

(C) Japan Radiological Society 2008

\section{Erratum to: Radiat Med (2008) 26:348-354 \\ DOI 10.1007/s11604-008-0239-6}

During correction of the above mentioned article, errors were inadvertently introduced.

In Table 1, in the column headed "Distance of filter movement" the proximal value of the case 1 should be "2.1", not " $21 "$.

The online version of the original article can be found under doi 10.1007/s11604-008-0239-6

K. Takayama $(\bowtie) \cdot$ T. Wada

Department of Interventional Neuroradiology, Ishinkai Yao

General Hospital, 1-41 Numa, Yao 581-0036, Japan

Tel. +81-72-948-2500; Fax +81-72-948-7950

e-mail: takayamaneuroivs@par.odn.ne.jp

H. Nakagawa $\cdot$ S. Iwasaki $\cdot$ T. Taoka $\cdot$ T. Miyasaka

K. Myouchin · M. Sakamoto · A. Fukusumi · K. Kichikawa

Department of Radiology, Nara Medical University, Kashihara,

Japan

I. Nakagawa $\cdot$ S. Kurokawa

Department of Neurosurgery, Ishinkai Yao General Hospital,

Yao, Japan

Table 1. Clinical and angiographic characteristics

\begin{tabular}{llll}
\hline \multirow{4}{*}{ Case } & \multicolumn{2}{l}{ Distance of filter movement } \\
\cline { 2 - 4 } & Distal & (Erroximal & (Correction) \\
\hline 1 & 0 & $\underline{21}$ & $\underline{2.1}$ \\
\hline
\end{tabular}

In Fig. 3, an arrow should appear in A and the legend has been partly revised. The figure is correctly shown in the next page. 

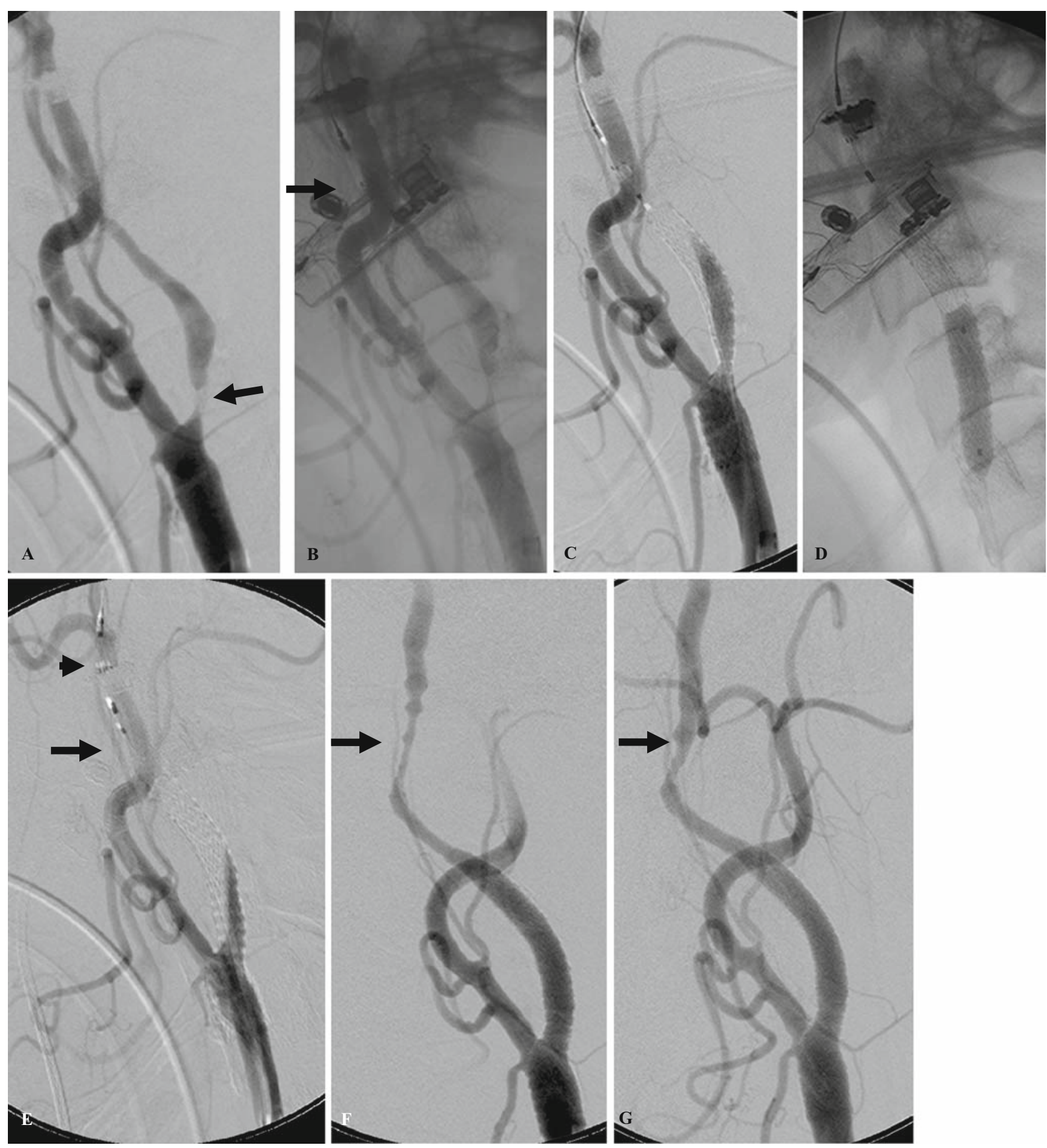

Fig. 3. Carotid artery stenting using the filter device: a case with no flow and vasospasm (case 4). A Left carotid angiogram shows 99\% stenosis of the ICA (arrow). B After filter replacement, the left carotid angiogram shows continuous flow through the filter. Arrow shows the initial position where the filter was implanted. C After stent deployment, the left carotid angiogram shows no flow through the ICA. D Percutaneous transluminal angioplasty (PTA) to the residual stenosis with a $6.0-\mathrm{mm}$ balloon. E Following

PTA, the left carotid angiogram still shows no flow through the ICA. The filter has moved from its initial indwelling position (indicated by the arrow) to the distal side by 1.7 of a vertebral body (arrowhead). F The left carotid angiogram immediately after filter captured shows flow of the ICA is restored. But highly developed vasospasm is recognized in the distal section of the ICA (arrow). G Five minutes later, the left carotid angiogram shows alleviation of the vasospasm in the ICA (arrow) 